\title{
QU
}

\section{AVALIAÇÃO DA QUALIDADE FÍSICO-QUÍMICA DE POLPAS DE FRUTAS CONGELADAS COMERCIALIZADAS NA CIDADE DE NOVA CRUZ-RN}

PESSOA, M. J. O. (IFRN/NC)*; SANTIAGO, A. F. J. (IFRN/NC).

\section{RESUMO}

O presente trabalho visou a análise físico-química de polpas de abacaxi, manga e maracujá congeladas, comercializadas na cidade de Nova Cruz-RN. Para a realização do trabalho foram utilizadas quatro amostras de diferentes polpas de frutas congeladas (uma de abacaxi, uma de manga e duas de maracujá) de marcas comerciais distintas (W, X, Y e Z respectivamente), com o objetivo de verificar a qualidade destas polpas, uma vez que, são consumidas in natura. Os resultados obtidos indicaram nas análises físico-químicas, das 4 amostras, duas (ambas de maracujá) estão em total acordo com a legislação, mas uma delas (manga) apresentou valor superior ao estabelecido para açucares totais, mas isso não a classifica como imprópria para o consumo humano. A polpa de abacaxi não apresenta padrões legais de identidade e qualidade.

PALAVRAS-CHAVE: Análises físico-químicas, polpas de frutas e qualidade das frutas.

\section{QUALITY ASSESSMENT PHYSICAL AND CHEMICAL AND FRUIT PULP FROZEN MARKETED IN NOVA CRUZ-RN}

\begin{abstract}
This study aimed to evaluation physicochemical pineapple pulp, mango and passion fruit, (everything frozen) commercialized in the city of Nova Cruz-RN. To carry out the study, we used four samples of different frozen fruit pulps (a pineapple, a mango and two of passion fruit) of different trademarks ( $W, X, Y$ and $Z$ respectively), with the purpose to check the quality of these pulps, since they are consumed in nature. The
\end{abstract}

results indicated that physico-chemical analysis showed that, of the four samples, two (both passion fruit) are in full compliance with the law, but one (manga) showed superior value to set for total sugars, but it does not classify as inappropriate for human consumption. The pineapple pulp has no legal standards of identity and quality.

KEY-WORDS: Physicochemical analysis, fruit pulps and Fruit quality. 


\section{AVALIAÇÃO DA QUALIDADE FÍSICO-QUÍMICA DE POLPAS DE FRUTAS CONGELADAS COMERCIALIZADAS NA CIDADE DE NOVA CRUZ-RN}

\section{INTRODUÇÃO}

As industrias de polpa de frutas vêm crescendo cada vez mais devido a facilidade de manuseio e a possibiidade de consumo das frutas nos períodos entressafras.

As polpas possuem características gerias, como: alta atividade de água, elevado potencial de óxido redução e pH baixo, sendo que a acidez enibe a microbiota deteriorante.

O preparo da polpas deve ser realizado apenas com frutas limpas, sadias e livres e qualquer material estranho em sua composição natural.

As polpas de frutas possuem algumas características gerais, como: alta atividade de água $(>0,95)$, potencial de óxido redução elevado e $\mathrm{pH}$ baixo, sendo a acidez um fator de inibição da microbiota deteriorante (PEREIRA et al, 2006).

A produção de popas de frutas é originada, em sua maioraia, por pequenos produtoes que, por falta de informações, não segem os devidos cuidados de higiene, o que pode comprometer as características do produto final.

Devido a isso, dar-se a necessidade da realização de análises desse material comecrcializado em dois supermercados da cidade de Nova Cruz - RN, de forma a compar os valores encontrados com os estabelecidos pela legislação.

\section{MATERIAIS E MÉTODOS}

\subsection{ANÁLISES FÍSICO-QUÍMICA}

A determinação do $\mathrm{pH}$ foi realizada em um potenciômetro, calibrado com soluções tampão $\mathrm{pH} \mathrm{4,0} \mathrm{e} \mathrm{7,0.} \mathrm{Foram} \mathrm{realizadas} \mathrm{três} \mathrm{medidas} \mathrm{de} \mathrm{pH}$ para cada amostra, sendo o valor final dado pela média aritmética simples das medidas e desvio padrão (PEREIRA et al, 2006).

O teor de Sólidos Solúveis foi determinado por refratômetria, utilizando-se refratômetro manual, a temperatura ambiente (entre 20 e $22 \stackrel{\circ}{\circ}$ ), e os resultados foram expressos em Brix, e corrigidos para 20 ㄷ (PEREIRA et al, 2006).

A determinação da acidez total foi realizada por volumetria com indicadro, usando-se solução de Hidróxido de sódio $(\mathrm{NaOH}) \quad 0,1 \mathrm{M}$ e a fenolftaleína $1 \%$ como indicador.

A análise sólidos totais foi realizada em um condutivímetro, e o valor foi expresso pela média araitmética e desvio padrão.

A determinação de açucares totais foi realizada pelo método de Lane-Eynon, que consiste na titulação da amostra em solução de Feling A e B, com indicador azul de metileno $1 \%$ sob aquecimento (Andrade, 2013).

\section{RESULTADOS E DISCUSSÕES}

Os resultados das análises físico-químicas foram expressos em média de três repetições e desvio padrão.

Com relação aos valores de acidez total expressa em ácido cítrico referente às 
polpas de manga $(0,50)$ e maracujá $(Y=3,16$ e $Z=2,60)$ e abacaxi $(0,32)$, presentes na tabela 1, estas se encontram de acordo com a legislação que estabelece os valores mínimos de 0,32 para manga, de 0,30 para abacaxi e 2,50 para o maracujá.

Tabela 1: Resultados encontrados para acidez em acido orgânico e pH.

\begin{tabular}{cccc}
\hline Marca / Polpa & $\begin{array}{c}\text { Acidez Total } \\
\text { (Ácido cítrico } \\
(\mathbf{g} / \mathbf{1 0 0 g}))\end{array}$ & $\mathbf{p H}$ & Legislação AT / pH \\
\hline W / Abacaxi & $0,32 \pm 0,03$ & $4,00 \pm 0,10$ & $>0,30 /-$ \\
X / Manga & $0,50 \pm 0,01$ & $3,89 \pm 0,01$ & $>0,32 />3,3$ e $<4,5$ \\
Y / Maracujá & $3,16 \pm 0,03$ & $3,10 \pm 0,10$ & $>2,50 />2,7$ e $<3,8$ \\
Z / Maracujá & $2,60 \pm 0,02$ & $3,09 \pm 0,10$ & $>2,50 />2,7$ e $<3,8$ \\
\hline
\end{tabular}

O mesmo pode ser observado com relação a Sólidos Solúveis (11,0 @BRIX, que é o valor mínimo estabelecido pela legislação de referencia para todas as polpas), como podemos observar na tabela 2 , que também apresentam os resultados conforme estabelecidos nas normas de padrão de qualidade apresentados para essas polpas.

Tabela 2: Resultados encontrados para Sólidos Solúveis e Sólidos Totais.

\begin{tabular}{cccc}
\hline Marca / Polpa & $\begin{array}{c}\text { Sólidos Solúveis } \\
\text { ( }{ }^{\circ} \text { Brix) }\end{array}$ & $\begin{array}{c}\text { Sólidos Totais } \\
\text { (g/100g) }\end{array}$ & $\begin{array}{c}\text { Legislação SL / } \\
\text { ST }\end{array}$ \\
\hline W / Abacaxi & $11 \pm 0,00$ & $15,6 \pm 0,16$ & $>11,00 /-$ \\
X / Manga & $11 \pm 0,00$ & $15,8 \pm 0,10$ & $>11,00 />14,00$ \\
Y / Maracujá & $11 \pm 0,00$ & $29,3 \pm 0,10$ & $>11,00 />11,00$ \\
Z / Maracujá & $11 \pm 0,00$ & $25,3 \pm 1,18$ & $>11,00 />11,00$ \\
\hline
\end{tabular}

Os valores de sólidos totais, observados na tabela 2, (manga = 15,8; maracujá = $29,3(\mathrm{Y})$ e $25,3(\mathrm{Z})$ e abacaxi $=15,6 \mathrm{~g} / 100 \mathrm{~g}$ ) se encontram dentro dos padrões para as polpas de fruta analisadas. No qual a legislação estabelece o mínimo de 11,00, 11,00 e $14,00 \mathrm{~g} / 100 \mathrm{~g}$ de sólidos totais para polpas de maracujá, abacaxi e manga respectivamente.

No que diz respeito à polpa de abacaxi, a legislação vigente não apresenta padrões físico-químicos de identidade e qualidade para esse produto. Neste trabalho foram realizadas determinações físico-químicas com o proposito de que possam servir de referência ou como base para outros trabalhos, ou ainda, para o estabelecimento de padrões de identidade e qualidade para a polpa dessa fruta.

Já que ainda não existem padrões para a polpa de abacaxi, os valores encontrados foram comparados com outros trabalhos de pesquisa, como podemos observar na tabela 3. Com relação às análises de $\mathrm{pH}(4,0)$, sólidos solúveis $\cong$ Brix $(11,0)$, acidez total titulável $(0,32)$ e açucares totais $(23,5)$, verificou-se que ambos diferem dos estudos de SILVA, OLIVEIRA e JALES, que obtiveram os valores de $\mathrm{pH}$ equivalente a 3,57 , sólidos solúveis 
totais (-BRIX) de 5,8, acidez de 0,4 e para açucares totais 4,2.

Esses valores também são diferentes dos encontrados por BUENOS et al (2002), que obteve $\mathrm{pH}$ de 4,25, sólidos solúveis de 6,0 @BRIX, acidez em acido cítrico equivalente a 0,17 e sólidos totais de 11,04.

A variação de acidez em acido cítrico pode ser explicada pelo grau de maturação do fruto, uma vez que, à medida que o fruto amadurece o teor de ácido cítrico diminui. (BUENO et al, 2002)

Tabela 3: Comparação

\begin{tabular}{cccccc}
\hline Autores & $\mathbf{p H}$ & $\begin{array}{c}\text { Sólidos } \\
\text { Solúveis } \\
\left({ }^{\circ} \text { Brix) }\right.\end{array}$ & $\begin{array}{c}\text { Sólidos } \\
\text { Totais } \\
(\mathbf{g} / \mathbf{1 0 0 g})\end{array}$ & $\begin{array}{c}\text { Acidez Total } \\
\text { (Ácido } \\
\text { cítrico(g/100g)) }\end{array}$ & $\begin{array}{c}\text { Açucares totais } \\
(\mathbf{g} / \mathbf{1 0 0 g})\end{array}$ \\
\hline $\begin{array}{c}\text { Bruna } \\
\begin{array}{c}\text { Silva, Oliveira } \\
\text { e Jales }\end{array}\end{array}$ & 4,57 & 11,0 & 15,6 & 0,32 & 23,4 \\
Buenos et al & 4,25 & 6,8 & - & 0,4 & 4,2 \\
\hline
\end{tabular}

Para as determinações dos açúcares totais, resultados expressos na tabela 4, os valores encontram-se dentro da faixa determinada pela legislação para as polpas de maracujá ( $Y=12,3$ e $Z=13,5)$, a qual estabelece um limite máximo de $18,00 \mathrm{~g} / 100 \mathrm{~g}$. E fora dos padrões (máximo de $17,00 \mathrm{~g}$ para cada $100 \mathrm{~g}$ ) para polpa de manga $(25,0)$. A determinação dos açúcares totais em polpa de frutas é importante para a verificação de possível adição de sacarose ao produto. Esses valores também podem ser afetados pelo grau de maturação da fruta colhida para o processamento. (GADELHA et al, 2009)

Tabela 4: Resultados encontrados para açucares totais.

\begin{tabular}{ccc}
\hline Marca / Polpa & $\begin{array}{c}\text { Açucares } \\
\text { totais }(\mathbf{g} / \mathbf{1 0 0 g})\end{array}$ & $\begin{array}{c}\text { Legislação } \\
\text { (Aç. Totais) }\end{array}$ \\
\hline W / Abacaxi & $23,5 \pm 0,10$ & $<15,00$ \\
X / Manga & $25,0 \pm 0,01$ & $<17,00$ \\
Y / Maracujá & $12,3 \pm 0,02$ & $<18,00$ \\
Z / Maracujá & $13,5 \pm 0,11$ & $<18,00$ \\
\hline
\end{tabular}

\section{CONCLUSÃO}

De acordo com os resultados obtidos e discutidos, observa-se que todas as polpas se apresentam dentro dos padrões fixados em legislação específica (Instrução normativa №. 1 de 7 de janeiro de 2000, e Resolução - RDC № 12, de 2 de janeiro de 2001). Com exceção dos valores obtidos nas determinações de açucares totais para a polpa de manga, que se encontram acima do valor estabelecido na legislação, mas não a classifica como impropria para o consumo humano.

Quanto às determinações para a polpa de abacaxi, não foram encontrados valores de referência na literatura pesquisada. Sendo, portanto, comparadas com os resultados obtidos por outros autores, como também comparados com os valores determinados 4a Semana de Química - IFRN, 2016 
para o suco de abacaxi presentes na Legislação.

Portanto, é de suma importância que seja realizada periodicamente a fiscalização para verificação da qualidade desses produtos alimentícios, com o intuito de evitar possíveis problemas tanto para o consumidor quanto para as indústrias produtoras de polpas de frutas.

\section{AGRADECIMENTOS}

Os autores agradecem ao Instituto Federal de Educação, Ciência e Tecnologia do Rio Grande do Norte - IFRN, Campus Nova Cruz pela disponibilização do espaço cedido na realização do projeto.

\section{REFERÊNCIAS}

PEREIRA, Joesse Maria de Assis Teixera Kluge et al. Avaliação da qualidade Físicoquímica, Microbiológica e Microscópica de polpas de frutas congeladas comercializadas na cidade de Viçosa - MG. Araraquara: Alim. Nutr.,v. 17, n. 4, p. 437 - 442, 2006.

ANDRADE, Rita Beatriz. Determinação de glicídios redutores em lactose pelo Método de Lane-Eynon em Leite. Laboratório Nacional Agropecuário - LANAGRO/RS, 2013. Disponível em: <http://www.agricultura.gov.br/arq_editor/file/Aniamal/Laborat\%C3\%B3rios/Metodos\% 20IQA/POA/Leite\%20e\%20Produtos\%20Lacteos/MET\%20POA\%2019\%2001\%20Acucares \%20em\%20leite.pdf>. Acessado em: 04/11/2015

SILVA, Maria Tamires Marques, OLIVEIRA, Jacqueline da Silva, JALES, Katiane Arrais. Avaliação da Qualidade físico-química de Polpas de Frutas congeladas comercializadas no interior do Ceará. Sobral - Ceará. Disponível em: <http://congressos.ifal.edu.br/index.php/connepi/\%20CONNEPI2010/paper/viewFile/112 4/922>. Acessado em: 09/11/2015

BUENO, Silvia M., LOPES, Maria do Rosário V., GRACIANO, Rejane A. S., FERNANDES, Eliana C. B., GARCIA-CRUZ, Crispin H. Avaliação da qualidade de polpas de frutas congeladas. Rev. Inst. Adolfo Lutz, 62(2):121-126, 2002.

GADELHA, Antônio José Ferreira, ROCHA, Clarice Oliveira da, VIEIRA, Fernando Fernandes, RIBEIRO, George do Nascimento. AVALIAÇÃo DE PARÂMETROS DE QUALIDADE FísICOQUÍMICOS DE POLPAS CONGELADAS DE ABACAXI, ACEROLA, CAJÁ E CAJU. Revista Caatinga, vol. 22, núm. 1, enero-marzo, 2009.

BRASIL. Agência Nacional de Vigilância Sanitária. Resolução RDC no 12, de 02/01/2001. Regulamento Técnico sobre padrões microbiológicos para alimentos. Diário Oficial da República Federativa do Brasil, Brasília, DF, 10 janeiro de 2001 